\title{
Evaluation of electromagnetic shielding effectiveness of multi-axial fabrics and their reinforced PES composites
}

\author{
RAMAZAN ERDEM \\ Department of Textile Technology, Serik G.S. Süral Vocational School of Higher Education, Akdeniz University, 07500 \\ Antalya, Turkey
}

MS received 18 June 2015; accepted 21 January 2016

\begin{abstract}
The usage of electrical and electronic equipments has been increasing in daily life, which has a potential hazardous impact on humans and other living organisms. In this paper, multi-axial fabrics containing steel yarns and carbon filaments, and their polyester (PES) resin-reinforced composites have been prepared for electromagnetic shielding applications. The electromagnetic shielding effectiveness (EMSE) of these structures was determined by using coaxial transmission line measurement technique. There were eight different multi-axial fabrics constructed. It was observed that the amount and the orientation of carbon and stainless steel yarns influenced the EMSE performances of multi-axial fabrics and their reinforced PES composites. The structures containing both carbon filaments and stainless steel yarns exhibited better EMSE than the ones including only one type of conductive yarns or filaments. Also, the EMSE performance of multi-axial fabrics was found better than their reinforced composites. The best EMSE results were obtained for the fabric, including two layers of yarns (steel and carbon) on top of each other in the centre with the angle of 45 and $-45^{\circ}$.
\end{abstract}

Keywords. Electromagnetic shielding effectiveness; multi-axial fabrics; reinforced composites; steel; carbon.

\section{Introduction}

Recently, the growing numbers in the usage of electrical and electronic equipments have been the main concern among researchers due to their potential health hazards on humans such as cancer and their negative impacts on the performance of the other electronic devices. Base stations, energy transmission lines, radars, military electronic devices, a.c. or d.c. motors, point of sale terminals, transformer stations, satellites, cellular phones, calculators, modems, digital computers, medical scanning devices, electric and electronic home appliances are some of the common examples of sources that produce electromagnetic waves and create electromagnetic fields $[1,2]$.

Figure 1 introduces the graphical representation of electromagnetic wave (EM) spectrum and related specific applications. Recently, EM waves in 1-10 GHz range are largely used especially, in wireless communication devices and local area networks. In the near future, it is expected that EM waves with higher frequencies will be utilized in many fields of everyday life as remarkable developments continue in information technology and electronic equipments [5]. Therefore, suitable shielding materials are needed to be developed to protect human health and prevent or limit the electromagnetic interference (EMI).

ramazanerdem@akdeniz.edu.tr,erdemramazan@gmail.com
EM are transverse waves consisting of electric and magnetic fields, and they are characterized by three main factors; wavelength, frequency and energy. Wavelength is described as the distance between two adjacent crests of the wave and is measured in metres. Frequency is the number of wave oscillations per second and measured in units of Hertz $(\mathrm{Hz})$. Wavelength and frequency are inversely related i.e., as the wavelength increases, frequency decreases. Energy is associated with individual photons in the wave. The amount of energy carried by an electromagnetic wave depends on wavelength. The shorter the wavelength, the higher the energy [6].

The source of the EMI is principally electrical with unwanted electromagnetic emission being radiated or conducted [2]. Electromagnetic shielding is defined as blocking the electromagnetic fields by using conductive or magnetic materials as barriers [7]. Effectiveness of a shield depends on the frequency of the EM, the distance of the shield from the source, the thickness of the shield and the shielding material composition. The shielding effectiveness (SE) in decibel $(\mathrm{dB})$ is an evaluation of EMI at a certain frequency range by the shielding material, and is calculated by the following formula (equation (1)):

$$
\mathrm{SE}=101 \mathrm{~g} \frac{P_{0}}{P_{\mathrm{t}}}=201 \mathrm{~g} \frac{E_{0}}{E_{\mathrm{t}}} 201 \mathrm{~g} \frac{H_{0}}{H_{\mathrm{t}}},
$$

where $P_{0}, E_{0}$ and $H_{0}$ are power, electric and magnetic field intensities to the shield and $P_{\mathrm{t}}, E_{\mathrm{t}}$ and $H_{\mathrm{t}}$ are the factors transmitted through the shield [8]. The attenuation of an EM is 


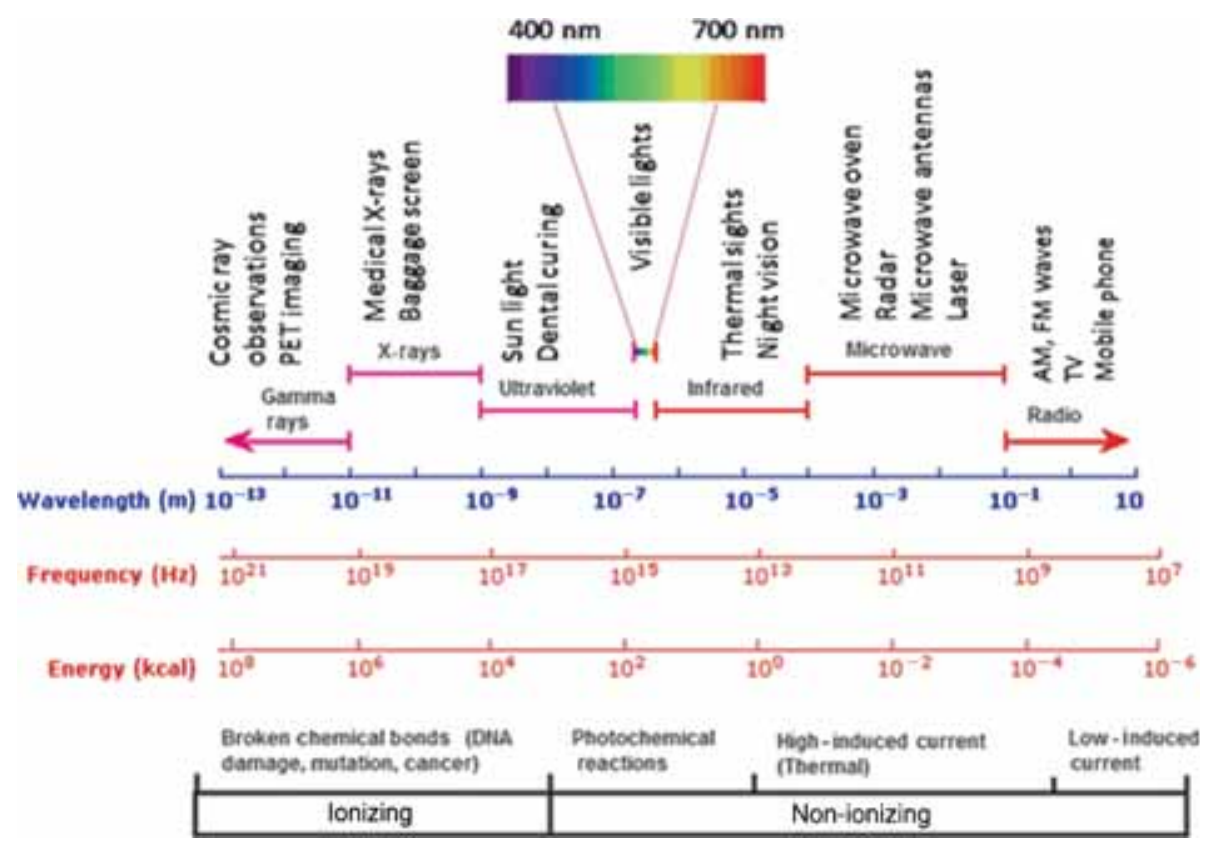

Figure 1. Graphical representation of electromagnetic wave spectrum and related applications $[3,4]$.

defined by three phenomena; (1) incident radiation which is reflected from the front surface of the shield, (2) the portion of the wave that crosses the shield surface and travels inside the shield wall as residual energy, and (2) transmitted wave [9].

Metals are claimed as the best electromagnetic shielding materials; however, they are highly expensive and heavy. Moreover, thermal expansion, oxidation and corrosion are considerable problems during usage [10]. On the other hand, conductive textile fabrics and textile-reinforced polymeric composites are potential electromagnetic shielding materials that can be successfully used in defense, electrical and electronic industries. The logic behind the construction of textile-based electromagnetic shielding material is to incorporate the conductive fillers such as metallic particles, metallized fibres, carbon fibres, metal wires (stainless steel, aluminium, copper), conductive yarns into the fabrics or textile-reinforced composites [9]. There are many records in literature related to the electromagnetic shielding effectiveness (EMSE) of woven fabrics [11-16], woven fabric-reinforced composites [10], knitted fabric-reinforced composites [17], co-woven knitted fabrics [18,19] and nonwovens [20,21].

Conductive textile-reinforced polymeric composites are also new alternatives for various shielding applications. The polymeric composite materials are manufactured by the combination of different materials (the matrix, reinforcement and conductive fillers) that form on a macroscale. These constituent materials do not dissolve but completely merge into each other [22]. The advantages of using such composite materials are flexibility, light weight, effective EMI protection, efficient radiofrequency interference protection and thermal expansion matching [23]. In the case of textile-reinforced polymeric composites, the matrix also serves to protect the textile structures from external damage and environmental attack.

The usage of multi-axial fabrics and their composites has significantly increased in terms of construction of various composite structures that are subjected to complex loads. Multi-axial fabrics contain multiple layers of continuous fibre strands that are generally stitched to each other with yarns or warping loops. The fibres in each layer can be oriented in different directions such as 0, 30, 45, 60 and $90^{\circ}$ [24]. There are many different studies that have been carried out regarding the mechanical properties and geometric preforming of stitched multi-axial textile-reinforced composites [25,26]; however, the number of studies related to electromagnetic shielding of these structures are limited [27].

The motivation behind the present study is to prepare multi-axial textile (without stitching) fabrics and their reinforced composites by using specifically designed metal frame and hand lay-up technique, and to analyse the EMSE of these structures. For this purpose, thermoset polyester (PES) resin was chosen as the matrix material due to its lower costs of material and manufacturing and easier processing compared to thermoplastics [28,29]. Also, poor bonding between filler and thermoplastic matrices is quite common which affects negatively the strength and ductibility of a composite [30]. Stainless steel yarns and carbon filament yarns were used as the reinforced materials because of their excellent conductivity properties. Impacts of yarn type and fabric structure to EMSE properties were investigated. Various steps followed to produce conductive multiaxial textile-reinforced PES composites are described in section 2 . 


\section{Experimental}

\subsection{Preparation of textile-reinforced composites}

In this study, conductive multi-axial textile fabrics and the reinforced composites were prepared and the EMSE of the structures was investigated. To form the multi-axial textile fabrics, continuous stainless steel yarn (Bekinox ${ }^{\circledR} \mathrm{VN}$ $12 / 2 \times 275 / 175 \mathrm{~S} / 316 \mathrm{~L}$, Beakart) with a linear density of 505 tex and carbon ribbon shape filament yarn $(3 \mathrm{~K}$ A-38, DowAksa) with a linear density of 200 tex were chosen as reinforcement and conductive materials.

A rectangular metal frame $(15 \times 25 \mathrm{~cm})$ was also designed that had grooves created at $2 \mathrm{~mm}$ intervals on each border. Multi-axial textile fabrics were formed by placing the steel yarns and carbon filament yarns regularly through the grooves on the metal frame. In this way, several types of topologies were obtained as defined in table 1 and showed in figure 2 . Then, the metal frame was properly placed into the wooden mould and the thermoset PES resin was poured into the mold to yield the final composite structure, which was subsequently left for $48 \mathrm{~h}$ at room temperature for complete drying and curing. As the carbon filament yarn is highly brittle and relatively inflexible, it has been carefully placed on the metal frame to establish the uniform multi-axial fabric structure without any fibre breakage.

Thermoset polyester (PES) resin was used to prepare the textile-reinforced composites by hand lay-up technique. Each multi-axial textile fabric was laid on a flat and smooth surface inside the rectangular shape $(15 \times 25 \mathrm{~cm})$ wooden mould, then the polyester resin was poured onto the fabrics in order to yield the final composite structures. For drying and curing processes, the resin-added fabric structures were maintained at room temperature for $48 \mathrm{~h}$. The obtained composite laminates were approximately $4 \mathrm{~mm}$ in thickness. Each of the multi-axial fabrics and reinforced composite structures were weighed to find out the amount of carbon and steel yarns used within the construction. Also, for composite structures, steel and carbon fibre volume fraction was calculated according to ASTM D2584 by using the following formula (equation (2)):

$$
V_{\mathrm{f}}=\left[Q_{\mathrm{m}} \cdot W_{\mathrm{f}} / Q_{\mathrm{m}} \cdot W_{\mathrm{f}}+Q_{\mathrm{f}} \cdot W_{\mathrm{m}}\right],
$$

where $V_{\mathrm{f}}$ is the volume fraction of fibres, $W_{\mathrm{f}}$ the weight of fibres, $W_{\mathrm{m}}$ the weight of matrix, $Q_{\mathrm{f}}$ the density of fibres and $Q_{\mathrm{m}}$ the density of matrix [31].

\subsection{Measurement of electromagnetic shielding effectiveness}

EMSE of both the multi-axial textile fabric structures and the reinforced PES composites was determined according to the ASTM D4935-10 standards by using coaxial transmission line measurement technique in the frequency range of 15$3000 \mathrm{MHz}$. The compact testing equipment (Electro-Metrics Inc., model EM-2107 A, USA) was utilized to measure EMSE of the materials. The reflectivity, absorption and transmissibility of the electromagnetic wave power of the fabrics and composites were evaluated by using a network analyzer (Rohde \& Schwarz, ZVL/9 kHz-13.6 GHz) with two coaxial connectors and two attenuators $(10 \mathrm{~dB})$, generating and receiving EM signals (figure $3 \mathrm{a}$ ). This standard determined the EMSE of the textile structures using the insertion-loss method.

Two specimens were required to carry out the EMSE assessment; one for the reference and another for the loaded samples (multi-axial fabrics and their reinforced PES

Table 1. Nomenclatures and definitions of multi-axial textile fabrics and reinforced PES composites.

\begin{tabular}{|c|c|}
\hline Nomenclatures & Definition \\
\hline C090FA & One layer of carbon yarn perpendicular to each other (angle is $0-90^{\circ}$ ) as fabric \\
\hline C090PC & One layer of carbon yarn perpendicular to each other (angle is $0-90^{\circ}$ ) as PES composite \\
\hline S090FA & One layer of steel yarn perpendicular to each other (angle is $0-90^{\circ}$ ) as fabric \\
\hline S090PC & One layer of steel yarn perpendicular to each other (angle is $0-90^{\circ}$ ) as PES composite \\
\hline C45FA & One layer of carbon yarn placed in between course and wale directions (angle is $45,-45^{\circ}$ ) as fabric \\
\hline $\mathrm{C} 45 \mathrm{PC}$ & One layer of carbon yarn placed in between course and wale directions (angle is $45,-45^{\circ}$ ) as PES composite \\
\hline S45FA & One layer of steel yarn placed in between course and wale directions (angle is $45,-45^{\circ}$ ) as fabric \\
\hline S45PC & One layer of steel yarn placed in between course and wale directions (angle is $45,-45^{\circ}$ ) as PES composite \\
\hline RSC090FA & Two layers of yarn (steel and carbon) exactly on top of each other in course and wale directions (angle $0-90^{\circ}$ ) as fabric \\
\hline RSC090PC & $\begin{array}{l}\text { Two layers of yarn (steel and carbon) exactly on top of each other in course and wale directions (angle } 0-90^{\circ} \text { ) as PES } \\
\text { composite }\end{array}$ \\
\hline RSC45FA & $\begin{array}{l}\text { Two layers of yarn (steel and carbon) exactly on top of each other in between course and wale directions }\left(45,-45^{\circ}\right) \text { as } \\
\text { fabric }\end{array}$ \\
\hline RSC45PC & $\begin{array}{l}\text { Two layers of yarn (steel and carbon) exactly on top of each other in between course and wale directions }\left(45,-45^{\circ}\right) \text { as } \\
\text { PES composite }\end{array}$ \\
\hline ESC090FA & Two layers of yarn (steel and carbon) on top of each other incentre with the angle of $0-90^{\circ}$ as fabric \\
\hline ESC090PC & Two layers of yarn (steel and carbon) on top of each other incentre with the angle of $0-90^{\circ}$ as PES composite \\
\hline ESC45FA & Two layers of yarn (steel and carbon) on top of each other incentre with the angle of $45-90^{\circ}$ as fabric \\
\hline ESC45PC & Two layers of yarn (steel and carbon) on top of each other incentre with the angle of $45-90^{\circ}$ as PES composite \\
\hline
\end{tabular}



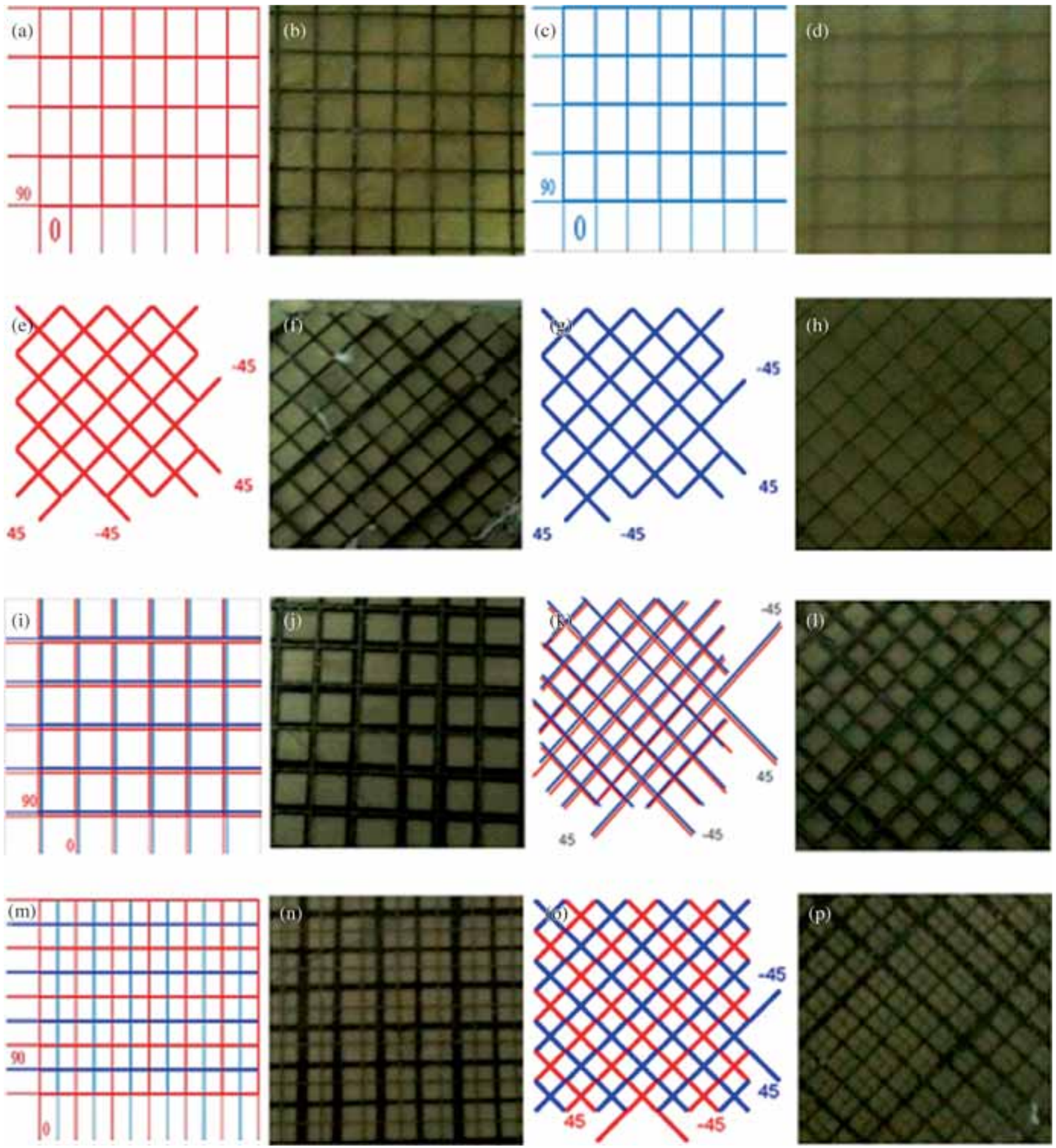

Figure 2. Various topologies of multi-axial fabrics and reinforced PES composites: (a) C090FA; (b) C090PC; (c) S090FA; (d) S090PC; (e) C45FA; (f) C45PC; (g) S45FA; (h) S45PC; (i) RSC090FA; (j) RSC090PC; (k) RSC45FA; (l) RSC45PC; (m) ESC090FA; (n) ESC090PC; (o) ESC45FA and (p) ESC45PC.

composites). The specimen dimension was determined as $133 \mathrm{~mm}$, same as the diameter of the outer ring dimension (figure 3b). EMSE was calculated by comparing the difference in attenuation of a reference specimen to the loaded specimen, taking into account the incident and transmitted power. EMSE of the samples was measured in decibels $(\mathrm{dB})$ and calculated by the following relation (equation (2)):

$$
\operatorname{EMSE}(\mathrm{dB})=10 \log \frac{P_{\text {out }}}{P_{\text {in }}},
$$



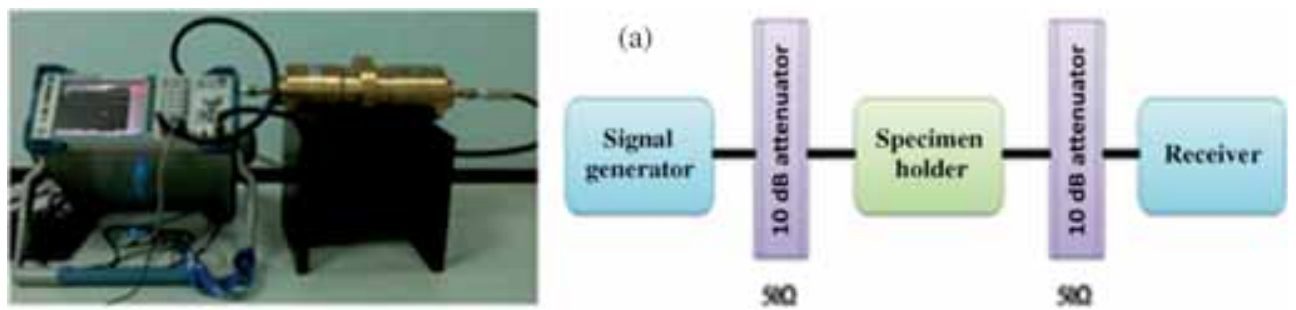

(b)
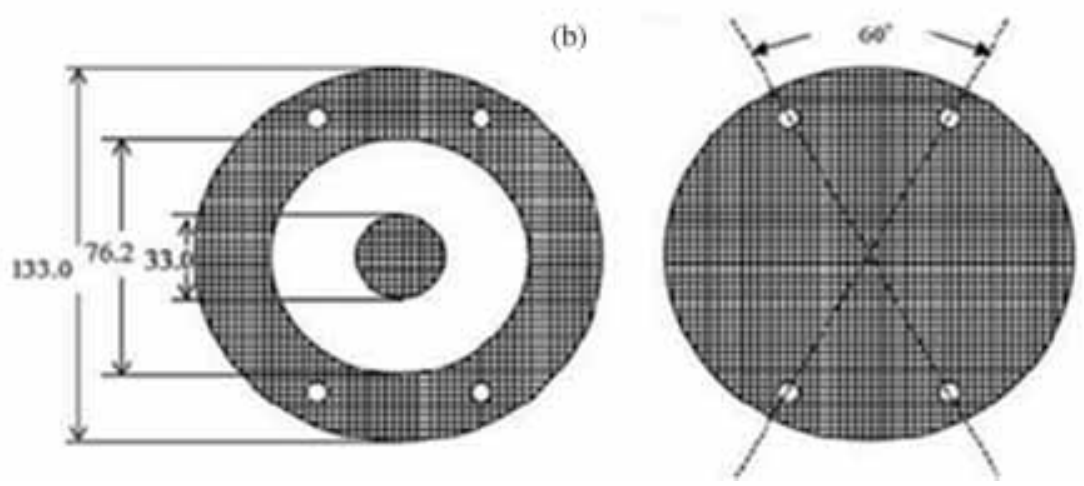

Figure 3. Testing equipment (Electro-Metrics Inc., model EM-2107 A) for EMSE analysis.

Table 2. The properties of multi-axial fabrics and reinforced PES composites.

\begin{tabular}{|c|c|c|c|c|c|c|c|c|c|}
\hline \multicolumn{4}{|c|}{ Multi-axial fabrics } & \multicolumn{6}{|c|}{ Reinforced PES composites } \\
\hline \multirow[b]{2}{*}{ Samples } & \multicolumn{2}{|c|}{ Weight $\left(\mathrm{g} \mathrm{m}^{-2}\right)$} & \multirow[b]{2}{*}{ Samples } & \multirow{2}{*}{$\begin{array}{l}\text { Composite } \\
\text { weight } \\
\left(\mathrm{g} \mathrm{m}^{-2}\right)\end{array}$} & \multirow{2}{*}{$\begin{array}{l}\text { Matrix } \\
\text { weight } \\
\left(\mathrm{g} \mathrm{m}^{-2}\right)\end{array}$} & \multirow{2}{*}{$\begin{array}{c}\text { Resin } \\
\text { density } \\
\left(\mathrm{g} \mathrm{cm}^{-3}\right)\end{array}$} & \multirow{2}{*}{$\begin{array}{c}\text { Steel fibre } \\
\text { density } \\
\left(\mathrm{g} \mathrm{cm}^{-3}\right)\end{array}$} & \multirow{2}{*}{$\begin{array}{c}\text { Carbon fibre } \\
\text { density } \\
\left(\mathrm{g} \mathrm{cm}^{-3}\right)\end{array}$} & \multirow{2}{*}{$\begin{array}{l}\text { Fibre } \\
\text { volume } \\
\text { fraction }\end{array}$} \\
\hline & Carbon & Steel & & & & & & & \\
\hline C090FA & 87 & XXX & C090PC & 2978.64 & 2891.64 & 1.128 & XXX & 1.78 & 0.018 \\
\hline S090FA & XXX & 229.15 & S090PC & 3060.28 & 2831.13 & 1.128 & 8 & XXX & 0.011 \\
\hline C45FA & 91.72 & XXX & $\mathrm{C} 45 \mathrm{PC}$ & 2991.88 & 2900.16 & 1.128 & XXX & 1.78 & 0.019 \\
\hline S45FA & $\mathrm{XXX}$ & 232.93 & $\mathrm{~S} 45 \mathrm{PC}$ & 3077.93 & 2845 & 1.128 & 8 & $\mathrm{XXX}$ & 0.011 \\
\hline RSC090FA & 87.31 & 224.74 & RSC090PC & 3030.96 & 2718.91 & 1.128 & 8 & 1.78 & 0.013 \\
\hline RSC45FA & 92.04 & 228.2 & RSC45PC & 3041.36 & 2721.12 & 1.128 & 8 & 1.78 & 0.013 \\
\hline ESC090FA & 87 & 225.05 & ESC090PC & 3100.62 & 2788.57 & 1.128 & 8 & 1.78 & 0.012 \\
\hline ESC45FA & 91.72 & 229.15 & ESC45PC & 3116.38 & 2795.51 & 1.128 & 8 & 1.78 & 0.013 \\
\hline
\end{tabular}

Note: XXX means no results of content available.

where decibel $(\mathrm{dB})$ is the unit that defines the power ratio which is used for specifying the SE, $P_{\text {out }}$ is the output power (watts) and $P_{\text {in }}$ the input power (watts) in the reference sample.

\section{Results and discussion}

\subsection{Structural properties of fabrics and reinforced composites}

Microstructural observation of several longitudinal and cross-sections of the composite materials indicated good integration of carbon and stainless steel yarns with the PES matrix. Various types of conductive multi-axial textile structures have been aimed to be prepared, because hielding material must be conductive to hinder the passage of electric fields and also highly permeable to hamper the passage of magnetic fields [15]. On the other hand, the amount and the orientation of carbon and stainless steel yarns influenced the EMSE performance of multi-axial fabrics and reinforced PES composites.

The properties of each multi-axial fabric and reinforced PES composite are presented in table 2. It is obvious that the weight of the multi-axial fabrics constructed with steel yarns found to be greater than the fabrics that included only carbon filament yarns. This was related to the difference in linear density of the yarns used in the fabric construction. Regarding fibre volume fraction results, no remarkable distinctions were obtained among the composite samples. As a result of that yarn type, placements were more focussed in terms of determining the EMSE performance of the structures. 


\subsection{EMSE performance of fabrics and reinforced composites}

For EMI shielding, there are two main mechanisms necessary; reflection and absorption. In the case of reflection of $\mathrm{EM}$, the shielding material must have mobile charge carriers (electrons and holes) which interact with the electromagnetic fields in the radiation. Also for significant absorption of EM, the shield ought to have electric and/or magnetic dipoles to be involved in an interaction with the electromagnetic fields in the radiation [30]. Therefore, enhancing the electrical conductivity of the composites improves their electromagnetic shielding ability. Steel and carbon are the potential candidates to fulfill this mission [32]. Carbon has low electrical resistivity and steel functions well by reflection due to the free electrons in it [33]. Figure 4 displays the variation of EMSE values of ESC090FA, RSC090FA, C090FA and S090FA multi-axial fabrics with the incident frequency in the range from 15 to $3000 \mathrm{MHz}$. Results indicate that ESC090FA reached a peak in the region between 600 and $900 \mathrm{MHz}$, respectively, and performed better EMSE than the other three fabrics. This can be explained by the amount of yarn used in the fabric structure as well as the placement of the yarns within the multi-axial form. As the openness between the yarns increases, the EMSE of the fabrics decreases [34]. Moreover, it is stated in the literature that the structures with smaller gaps between conductive fibres display higher overall EMSE at high frequencies, on the other hand, bigger gaps between conductive fibres exhibit higher overall EMSE at low frequency [4,35]. Figure $2 \mathrm{~m}$ clearly represents that carbon and steel yarns were placed on top of each other in center. This sort of placement generated a multi-axial form that possesses smaller pore size compared with the other fabric structures. Furthermore, this type of placement provides more conductive materials to be established in per unit

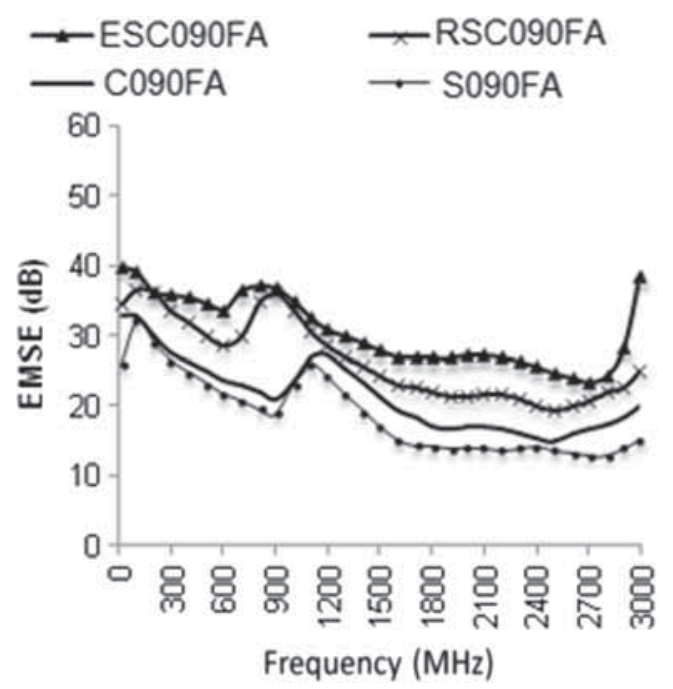

Figure 4. Variations in EMSE of multi-axial fabrics of ESC090FA, RSC090FA, C090FA and S090FA in the frequency range from 15 to $3000 \mathrm{MHz}$. area and creates more fibre interconnectivity within the construction. Therefore, ESC090FA fabric better prevented the penetration of the electromagnetic waves and produced the highest EMSE. On the other hand, all the fabrics displayed downward tendency with the increasing frequency.

Although some studies $[30,36]$ in the literature states that the metal filaments have better conductivity than carbon filaments, our findings represented that the fabrics and the composites with carbon yarns performed better EMSE than the ones containing steel yarns. Greater EMSE values were obtained for C090FA multi-axial fabric compared with S090FA fabric. This may be due to ribbon-like shape of the carbon yarn exhibited in figure $2 b$, where the pore sizes are narrower than the sizes obtained for S090FA fabric (figure 2d). As conductive yarns/filaments are closely placed, continuous conductive mesh paths can be generated easily that increases the EMSE [4]. Ribbon shape of the carbon filament yarns created a mesh path with the closely spaced yarns.

Figure 5 illustrates the variations of EMSE values of ESC090CO, RSC090CO, C090CO and S090CO reinforced PES composites with the incident frequency in the range from 15 to $3000 \mathrm{MHz}$. Findings revealed that the highest EMSE value was obtained for ESC090CO composite. It was observed that the EMSE of ESC090CO and RSC090CO showed increasing tendency until the region of 600$900 \mathrm{MHz}$, approximately, and then fell again as the frequency increased. On the other hand, EMSE of C090CO and S090CO increased until $900 \mathrm{MHz}$, respectively, then showed downward tendency with the increasing incident frequency. According to the figure, $\mathrm{C} 090 \mathrm{CO}$ presented better EMSE value than S090CO within the frequency range between 15 and $3000 \mathrm{MHz}$. This is probably due to the ribbon shape of the carbon yarn again, because multiple reflections occur during shielding where surface and interface characteristics of the shielding structure become very important.

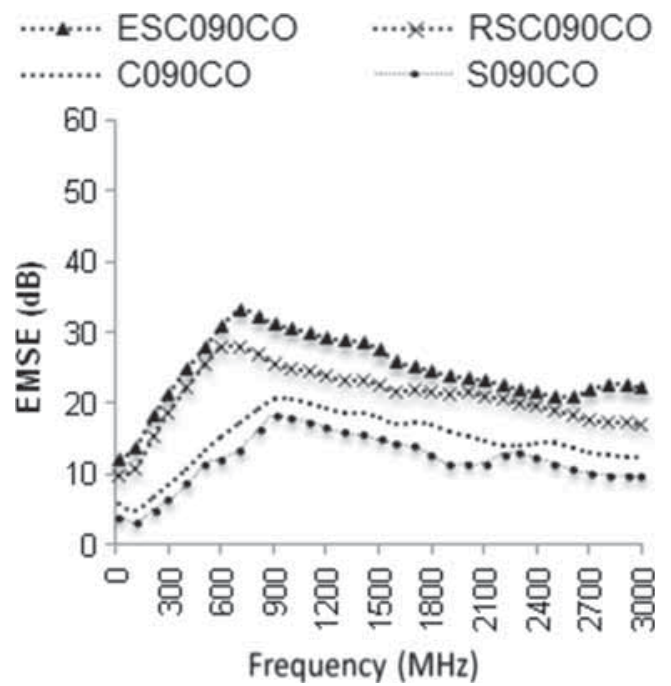

Figure 5. Variations in EMSE of reinforced PES composites of ESC090CO, RSC090CO, C090CO and S090CO in the frequency range from 15 to $3000 \mathrm{MHz}$. 


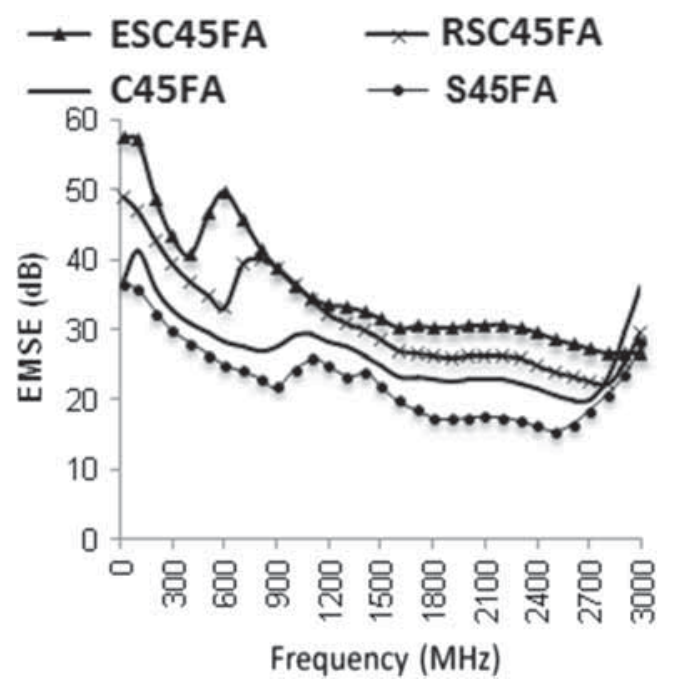

Figure 6. Variations in EMSE of multi-axial fabrics of ESC45FA, RSC45FA, C45FA and S45FA in the frequency range from 15 to $3000 \mathrm{MHz}$.

Large interface area created by ribbon shape carbon yarns induced the increase in EMSE performance [30]. In general, results proved that yarn type used in the composite structure, and the placement of yarns (centre or exactly top of each other) influenced the EMSE performance of the structures dramatically.

Figure 6 exhibits the variations of EMSE values of ESC45FA, RSC45FA, C45FA and S45FA multi-axial fabrics with the incident frequency in the range from 15 to $3000 \mathrm{MHz}$. According to the graph, the EMSE of ESC45FA was found greater than the other fabrics. All fabrics performed better EMSE in low frequencies compared with the high frequency range. In terms of EMSE, RSC45FA was more effective than C45FA and S45FA, which is a direct result of the fact that RSC45FA contains both steel and carbon yarns where more conductive field has been established per unit area.

Figure 7 displays the variations of EMSE values of ESC45CO, RSC45CO, C45CO and $\mathrm{S} 45 \mathrm{CO}$ reinforced PES composites with the incident frequency in the range from 15 to $3000 \mathrm{MHz}$. It was observed that ESC45CO displayed greater EMSE than other composite structures. It increased until around $400 \mathrm{MHz}$ and reached a peak, then started to decrease until $2700 \mathrm{MHz}$, then increased again slightly. Lowest EMSE value was obtained for $\mathrm{S} 45 \mathrm{CO}$, it increased in the range of $0-900 \mathrm{MHz}$ and reached a peak at $900 \mathrm{MHz}$, approximately, then fell until $2400 \mathrm{MHz}$ and remained steady between 2400 and $3000 \mathrm{MHz}$.

In general, shielding analysis proved that multi-axial fabrics showed slightly better EMSE than the reinforced PES composites. This may be due to the insulation property of polymeric materials since PES resin was used as the matrix to produce the composite structure, which might negatively influence the conductive characteristic of the composite at the end. Furthermore, insulating characteristics of PES might

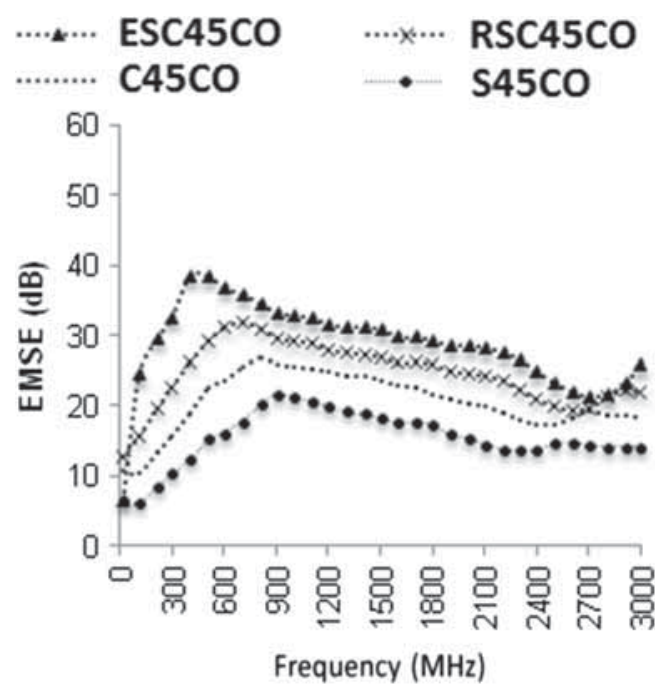

Figure 7. Variations in EMSE of reinforced PES composites of $\mathrm{ESC} 45 \mathrm{CO}, \mathrm{RSC} 45 \mathrm{CO}, \mathrm{C} 45 \mathrm{CO}$ and $\mathrm{S} 45 \mathrm{CO}$ in the frequency range from 15 to $3000 \mathrm{MHz}$.

prevent the effective contact between the conductive filaments in composites, and avoided the formation of an efficient conduction mesh network $[4,37]$. On the other hand, the multi-axial fabrics and reinforced PES composites constructed with carbon and/or steel yarns, which are placed in between course and wale directions (angle is $45,-45^{\circ}$ ) presented better EMSE performance than the structures that constitute yarns that are placed perpendicular to each other (angle is $0-90^{\circ}$ ). This might be related to the unknown data about the height of the electromagnetic waves (the distance between the crests and troughs) that have been used during our experiments.

\section{Conclusions}

In this study, the multi-axial fabrics including carbon filaments and stainless steel yarns, and their reinforced PES composites have been successfully prepared. The impacts of volume fraction, amount and orientation of carbon filament yarns and stainless steel yarns on electromagnetic shielding were investigated according to standard test method, ASTM D4935-10. For composite samples, the influence of the fibre volume fraction to EMSE properties was negligible. The amount, the type and the placement of the yarn sand/or filaments were effective on EMSE properties of the structures. Usage of both carbon filaments and stainless steel yarns increased EMSE of the structures. Structures including only carbon filaments displayed better EMSE than the ones containing only stainless steel yarns. Shielding analysis also showed that multi-axial fabrics exhibited slightly better EMSE than the reinforced PES composites. Our study verified that EMSE properties of the structures can be tailored by placing the yarns and/or filaments in different directions. Textile-reinforced polymeric composites could be potential 
alternatives to metallic materials in terms of electromagnetic shielding applications. Multi-axial forms can be improved by further attempts regarding changing the construction of the structures and the yarns/filament types. Also, flexibility of the conductive reinforced composites can continue to motivate researchers to develop novel electromagnetic shielding products that are used in many industrial fields.

\section{Acknowledgement}

I would like to thank Dr Erhan Sancak from Textile Engineering Department of Marmara University (Istanbul, Turkey) for his valuable support during the experimental part of this study.

\section{References}

[1] Cheng K B, Lee K C, Ueng T H and Mou K J 2002 Compos. Part A 331219

[2] Ozen M S, Sancak E, Beyit A, Usta I and Akalın M 2013 Text. Res. J. 83849

[3] http://www2.chemistry.msu.edu/faculty/reusch/VirtTxtJml/ Spectrpy/UV-Vis/spectrum.htm (10.11.2015)

[4] Roh J S, Chi Y S, Kang T J and Nam S W 2008 Text. Res. J. 78825

[5] Lapinsky S E and Easty A C 2006 J. Crit. Care 21267

[6] Sharma A K, Bhardwaj P, Singh K K and Dhawan S K 2014 Appl. Nanosci. 5635

[7] Cheng K B, Ramakrishna S and Lee K C 2000 J. Thermoplast. Compos. 13378

[8] Wang Y Y and Jing X L 2005 Polym. Advan. Technol. 16344

[9] Tezel S, Kavusturan Y, Vandenbosch G A E and Volski V 2013 Text. Res. J. DOI:10.1177/0040517513503728

[10] Chen H C, Lee K C, Lin J H and Koch M 2007 J. Mater. Process. Technol. 184124

[11] Cheng K B, Lee M L, Ramakrishna S and Ueng T H 2001 Text. Res. J. 7142

[12] Palamutcu S, Ozek A and Karpuz C 2010 Tekst. Konfeksiyon. 3199

[13] Su C I and Chern J T 2004 Text. Res. J. 7451
[14] Cheng K B, Cheng T W, Nadaraj R N, GiriDev V R and Neelakandan R 2006 J. Reinf. Plast. Comp. 25699

[15] Cheng K B, Cheng T W, Lee K C, Ueng T H and Hsing W H 2003 Compos. Part A 34971

[16] Ueng T H and Cheng K B 2001 Compos. Part A 321491

[17] Cheng K B, Ramakrishna S and Lee K C 2000 Compos. Part A 311039

[18] Chen H C, Lee K C and Lin J H 2004 Compos. Part A 351249

[19] Chen H C, Lin J H and Lee K C 2008 J. Reinf. Plast. Comp. 27187

[20] Ceken F, Erdogan H, Kayacan O and Ugurlu S S 2012 J. Text. I. 103669

[21] Zhu H, Chen P, Wu R and Zhang H 2007 Indian J. Fibre Text. 32391

[22] Rios-Soberanis C R, Cruz-Estrada R H, Rodriguez-Laviada J and Perez-Pacheco E 2012 DYNA 79115

[23] Clayton P R 1992 Introduction to electromagnetic compatibility, 1st edn (New York: Wiley)

[24] Wang Y J 2002 Appl. Compos. Mater. 981

[25] Loendersloot R, Lomov S V, Akkerman R and Verpoest I 2006 Compos. Part A 37103

[26] Saito H and Kimpara I 2006 Compos. Part A 372226

[27] Micheli D, Laurenzi S, Mariani Primiani V, Moglie F, Gradoni G and Marchetti M 2012 Aerospace EMC, Proceedings ESA Workshop on IEEE

[28] Verrey J, Wakeman M D, Michaud V and Manson J A E 2006 Compos. Part A 379

[29] Hull D and Clayne T W 1996 An introducton to composite materials, 2nd edn (Cambridge: Cambridge University Press) p 2

[30] Chung D D L 2001 Carbon 39279

[31] Messiry M E 2013 Alexandria Eng. J. 52301

[32] Shinagawa S, Kumagai Y and Urabe K 1999 J. Porous Mat. 6185

[33] Wong K H, Pickering S J and Rudd C D 2010 Compos. Part A 41693

[34] Perumalraj R and Dasaradan B S 2009 Indian J. Fibre Text. 34149

[35] Perumalraj R, Dasaradan B S, Anbarasu R, Arokiaraj P and Leo Harish S 2009 J. Fibre Text. 100512

[36] Li L and Chung D D L 1994 Composites 25215

[37] Vilcakova J, Saha P, Kresalek V and Quadrat O 2000 Synth. Met. 11383 